MAKÜ FEBED

ISSN Online: 1309-2243

http://dergipark.ulakbim.gov.tr/makufebed

Mehmet Akif Ersoy Üniversitesi Fen Bilimleri Enstitüsü Dergisi 8(1): 1-7 (2017)

The Journal of Graduate School of Natural and Applied Sciences of Mehmet Akif Ersoy University 8(1): 1-7 (2017)

Araştırma Makalesi / Research Paper

\title{
Heybeli (Afyonkarahisar) Jeotermal Alanı Hidrojeokimyasal Özellikleri ve Jeotermometre Uygulamaları
}

\author{
Selma DEMER*, Ümit MEMiş \\ Süleyman Demirel Üniversitesi, Mühendislik Fakültesi, Isparta \\ Geliş Tarihi (Received): 02.12.2016, Kabul Tarihi (Accepted): 12.01.2017 \\ $\square$ Sorumlu Yazar (Corresponding author)*: selmademer@sdu.edu.tr \\ (C) +902462111615 且 +902462370859
}

$\overline{o ̈ z}$

Heybeli jeotermal alanı Afyonkarahisar ilinde bulunan jeotermal sahalardan biridir. Çalışma alanındaki Paleozoyik yaşlı kuvarsit, kristalize kireçtaşı (mermer) ve kalkşistler ile Neojene ait çakıltaşı, kumtaşı, kireçtaşı kaya birimleri bölgedeki termal sular için muhtemel rezervuar kayacı oluşturur. Jeotermal suların sıcaklıkları $56^{\circ} \mathrm{C}$, EC değerleri 3440 ve $3490 \mu \mathrm{S} / \mathrm{cm}$ ve pH değerleri 6,53 ve 6,56 olarak ölçülmüştür. Heybeli jeotermal suları $\mathrm{Na}-(\mathrm{Ca})-\mathrm{HCO}_{3}-\mathrm{SO}_{4}$ su tipinde olup TDS, $\mathrm{Na}, \mathrm{SO}_{4}, \mathrm{~F}, \mathrm{Fe}, \mathrm{As}, \mathrm{B}$ değerleri ulusal ve uluslararası standartları aşmaktadır. Heybeli bölgesindeki jeotermal sularda yapılan rezervuar sıcaklığı hesaplamaları, alanda $75-106^{\circ} \mathrm{C}$ akışkan içeren bir sisteminin varlığını göstermektedir.

Anahtar Kelimeler: Afyonkarahisar-Heybeli, jeotermal sular, jeotermometre, hidrojeokimya

\section{Hydrogeochemical Features and Geothermometry Applications of Heybeli (Afyonkarahisar) Geothermal Field}

\begin{abstract}
Heybeli geothermal field is one of the geothermal systems in Afyonkarahisar and environ. Paleozoic quartzites, crystallized limestones (marble), and calc schists and Neogene pebbles, sandstone, limestone units are probable reservoir rocks of the geothermal waters in the study area. Temperature measurements of the geothermal waters are $56{ }^{\circ} \mathrm{C}$, EC values are between $3440-3490 \mu \mathrm{S} / \mathrm{cm}$ and $\mathrm{pH}$ values are between 6,53-6,56. Heybeli geothermal waters can be considered as $\mathrm{Na}-(\mathrm{Ca})-\mathrm{HCO}_{3}-\mathrm{SO}_{4}$ type exchange waters. And these geothermal waters TDS, $\mathrm{Na}$, $\mathrm{SO} 4, \mathrm{~F}, \mathrm{Fe}, \mathrm{As}$ and $\mathrm{B}$ values are higher than the national and international standards. The reservoir temperature calculations of Heybeli geothermal waters indicate the existence of a system containing fluid in the $75-106^{\circ} \mathrm{C}$.
\end{abstract}

Keywords: Afyonkarahisar-Heybeli, geothermal waters, geothermometer, hydrogeochemistry

\section{GiRiş}

İnceleme alanı Afyonkarahisar ilinin yaklaşık $35 \mathrm{~km}$ güneydoğusundadır. Heybeli jeotermal alanının, çağlar boyunca yoğun bir şekilde kaplıca olarak kullanıldığı bilinmektedir. Bolvadin belediyesine ait Heybeli Termal Tesisleri'nin ısıtma ve balneolojik kullanım suyu gereksinimini karşılamak amacıyla açılmış olan $\mathrm{H}-1 / \mathrm{A}, \mathrm{H}-3$ 
ve $\mathrm{H}-4$ kuyuları bulunmaktadır. $\mathrm{H}-1 / \mathrm{A}$ kuyusu halen Heybeli Termal Tesisleri gereksiniminin karşılanması amacıyla, H-4 kuyusu sahadaki bir bölüm devre-mülk konutun jeotermal su gereksiniminin karşılanması için kullanılmakta, H-3 kuyusu ise kullanılmamaktadır (Gırbalar, 2008). Bölgede jeotermal amaçlı jeolojik, hidrojeokimyasal çalışmalar çeşitli araştırmacılar tarafından yapılmıştır. Erişen (1972), Afyonkarahisar-Heybeli sahasının jeolojisi ve jeotermal enerji olanaklarını araştırmıştır. Mutlu (1996), Afyonkarahisar jeotermal alanları termal sularının jeokimyasal değerlendirmesini yapmış, Heybeli-Karaburun bölgesindeki suların Na$\mathrm{HCO} 3$ karakterinde olduğunu belirlemiş, akışkanmineral denge durumlarını incelemiş ve jeotermometre uygulamalarını yaparak rezervuar sıcaklıklarını hesaplamıştır. Gemici ve Tarcan (2004), Afyonkarahisar Heybeli termal suları ile ilgili yaptıkları çalışmada, bu termal suların ısıtma, sera, banyo, yüzme ve balneolojik amaçlara uygun olduğunu ancak bazı major $(\mathrm{Ca}$, $\mathrm{Mg}, \mathrm{Na}$ ve SO4) ve ikincil iyon konsantrasyonları (özellikle As) açısından maden suyu olarak kullanımının uygun olmadığını belirtmiştir. Bu çalışmada, Heybeli jeotermal alanındaki suların hidrojeokimyasal özelliklerinin belirlenmesi ve jeotermal suyun rezervuar sıcaklığının araştırııması amaçlanmıştır.

\section{MATERYAL VE YÖNTEM}

Çalışmalar, arazi çalışmaları ve laboratuar çalışmaları olmak üzere iki grupta toplanabilir. Yapılan arazi çaIışmalarında 2 adet jeotermal su kuyusundan ve 1 adet yeraltısuyu kuyusundan örnek alınmıştır. Örnekler 0,45 $\mu \mathrm{m}$ geçirgenliğindeki filtre ile süzülmüştür. Örnek şişelerinden biri katyon örneklerinin korunması amacıyla derişik $\mathrm{HNO}_{3}$ ilave edilerek asitlendirilmiş, anyon analizi için alınan diğer örnek şişesine ise asit eklenmemiştir. Arazi çalışmalarında sıcaklık ( $T$ ), hidrojen iyonu aktivitesi $(\mathrm{pH})$, elektriksel iletkenlik (EC) gibi in-situ ölçümleri taşınabilir cihazlarla ölçülmüş, alkalinite-asidite titrimetrik yöntemle belirlenmiştir. Alınan örneklerin hidrojeokimyasal analizleri standart metotlar (APHA-AWWAWEF, 2005) kullanılarak Süleyman Demirel Üniversitesi Jeotermal Enerji, Yeraltısuyu ve Mineral Kaynakları Araştırma ve Uygulama Merkezinde ICP-OES ve iyon kromatografisi cihazlarında gerçekleştirilmiştir. Analiz sonuçları için herhangi bir doğruluk ve kesinlik deneyleri yapılmamış olmakla beraber analiz edilen sulara ait yük-denge oranlarının $\% 5$ 'den az oluşu nedeniyle (Tablo 1), sonuçlar güvenilir olarak kabul edilmiştir. Hidrojeokimyasal analiz sonuçları AquaChem v.3.7 (Calmbach, 1999) ve SOLMINEQ.88 PC/SHELL (Kharaka et al., 1988) bilgisayar programları kullanılarak değerlendirilmiştir.

\section{BULGULAR VE TARTIŞMA}

\section{Jeoloji}

Heybeli bölgesinde temelde Paleozoyik yaşlı şistler bulunmaktadır. Bu metamorfik temeli killi şist, mikaşist, kalkşist, fillit, kuvarsit, kuvarslı şist ve kuvarsit şistler oluşturur. Şistlerin üzerine geçişli olarak mermer ve kalkşistler yer alır. Bunların üzerine açısal uyumsuzlukla Neojen çökelleri gelir. Gözenekli gölsel kireçtaşı, killi kireçtaşı, marn, tüfit, çakıltaşı, kumtaşı, silt ile temsil edilen Neojen çökellerin maksimum kalınlığı 300 m. dir. Traverten ve alüvyon ise en genç birimleridir. Genç volkanik etkinliğe bağlı kayalar Neojen çökelleri arasındaki tüfitler ile Neojen sonu ve/veya sonrası yaşı bazaltlardır. Alanda gözlenen genel kırık hatları KD-GB ve KB-GD yönlü eğim atımlı normal faylarla temsil edilir ve bu kırık çizgileri Neojen sonu ve/veya sonrası yaşlıdır. Paleozoyik yaşlı kuvarsit, kristalize kireçtaşı (mermer) ve kalkşistler ile Neojene ait çakıltaşı, kumtaşı, kireçtaşı kaya birimleri bölgedeki termal sular için muhtemel rezervuar kayacı oluşturur (Şekil 1; Erişen, 1972; Erişen ve ark, 1984; Mutlu, 1996; Akkuş ve ark., 2005; Gemici ve Tarcan, 2004).

\section{Hidrojeokimya}

Çalışma kapsamında Heybeli jeotermal sahasından 2 adet jeotermal su, 1 adet yeraltısuyu örneği alınmıştır. Çalışma alanındaki sulara ait in-situ ve hidrojeokimyasal analiz sonuçları Tablo 1'de verilmiştir.

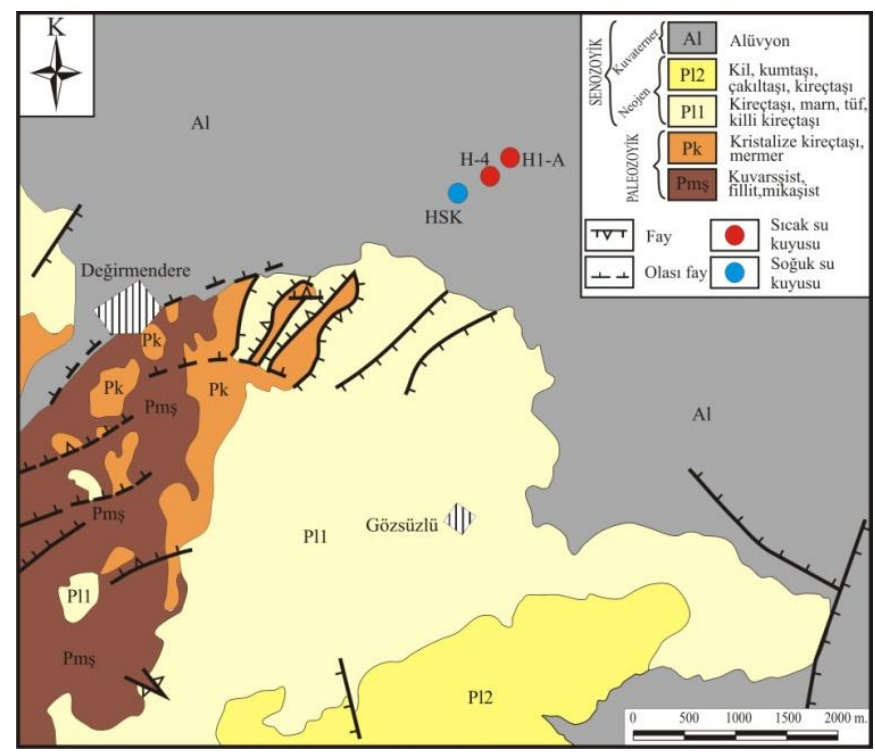

Şekil 1. Heybeli jeotermal alanının jeoloji haritası (Erişen, 1972'den basitleştirilerek)

Jeotermal su örneklerinin sıcaklıkları $56^{\circ} \mathrm{C}$, EC değerleri 3440 ve $3490 \mu \mathrm{S} / \mathrm{cm}$ ve $\mathrm{pH}$ değerleri 6,53 ve 6,56 olarak ölçülmüştür. Yeraltısuyu örneğinin ise sıcaklığı 
$11,4^{\circ} \mathrm{C}, \mathrm{pH}$ değeri 6,75 ve elektriksel iletkenlik değeri ise $1330 \mu \mathrm{S} / \mathrm{cm}$ olarak ölçülmüştür. Çalışma alanındaki suların hidrojeokimyasal fasiyesini belirlemek amacıyla kimyasal analiz sonuçları, Piper diyagramı üzerine yerleştirilmiştir. Bu diyagrama göre, jeotermal sular $\mathrm{Na}-$ (Ca)- $\mathrm{HCO}_{3}-\mathrm{SO}_{4}$ tipli sular fasiyesine girmektedir. Yeraltısuları ise $\mathrm{Ca}-(\mathrm{Na})-\mathrm{HCO}_{3}-\left(\mathrm{SO}_{4}\right)$ tipli sular fasiyesindedir (Şekil 2; Demer ve Memiş, 2015). Schoeller yarı logaritmik diyagramına göre ise jeotermal sularda hakim iyon dağılımı katyonlar için $\mathrm{Na}+\mathrm{K}>\mathrm{Ca}>\mathrm{Mg}$, anyonlar için $\mathrm{HCO}_{3}>\mathrm{SO}_{4}>\mathrm{Cl}$ olup, soğuk yeraltısuyunda hakim iyon dağılımı katyonlar için $\mathrm{Ca}>\mathrm{Na}+\mathrm{K}>\mathrm{Mg}$, anyonlar için $\mathrm{HCO}_{3}>\mathrm{SO}_{4}>\mathrm{Cl}$ şeklindedir (Şekil 3). Heybeli bölgesindeki jeotermal suların kimyasal analiz sonuçları göz önüne alındığında TDS, $\mathrm{Na}, \mathrm{SO}_{4}, \mathrm{~F}, \mathrm{Fe}, \mathrm{As}$, B değerlerinin ulusal (DMSHY, 2004; ITASHY, 2005) ve uluslararası (WHO, 2006) içme suyu standartlarını aştığı görülmektedir (Tablo 1).

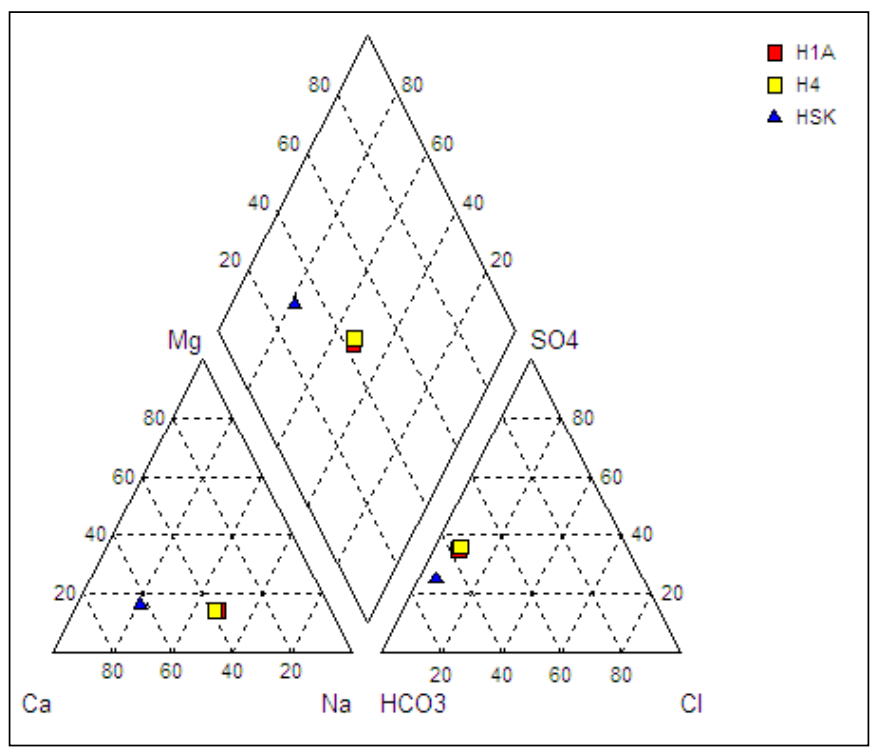

Şekil 2. Çalışma alanındaki suların Piper üçgen diyagramındaki dağılımları

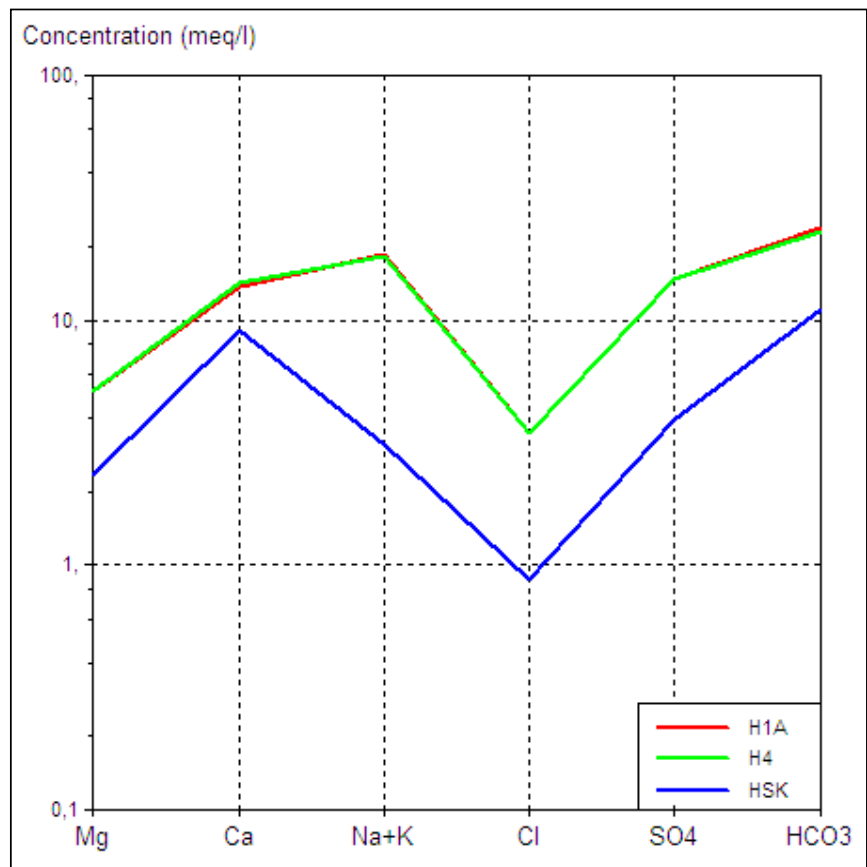

Şekil 3. Çalışma alanındaki suların Scholler yarı logaritmik diyagramdaki dağııımları

\section{Rezervuar Sıcaklığının Belirlenmesi}

\section{a) Silika ve katyon jeotermometreleri}

Çalışma alanındaki jeotermal suların silika jeotermometreleri ve katyon jeotermometreleri ile rezervuar sıcaklıkları hesaplanmıştır (Tablo 2-3). Kuvars jeotermometrelerinin ölçülen kuyu başı sıcaklıkları dikkate alınarak $75-90^{\circ} \mathrm{C}$ civarında bir rezervuar sıcaklığı yansıttığı söylenebilir. Kalsedon jeotermometreleri ile de 58-60 ${ }^{\circ} \mathrm{C}$ civarında bir rezervuar sıcaklığı hesaplanmıştır. Kalsedon jeotermometreleri kuvars jeotermometrelerine göre daha düşük sıcaklıklar vermiştir. Kalsedon jeotermometreleri kullanılarak hesaplanan rezervuar sıcaklıklarının, kuyu başı sıcaklığına yakın sonuçlar vermesi nedeniyle, Heybeli sahası için kuvars jeotermometrelerinin rezervuar sıcaklıklarını daha iyi yansıttığı söylenebilir. K-Mg ve Na-K-Ca jeotermometreleri dışında kalan diğer katyon jeotermometreleri daha yüksek sonuçlar vermiştir (Tablo 3). 
Tablo 1. Heybeli jeotermal alanından alınan suların in-situ ve hidrojeokimyasal analiz sonuçları

\begin{tabular}{|c|c|c|c|c|c|c|}
\hline \multirow{2}{*}{ Parametreler } & \multicolumn{3}{|c|}{ Ornek adı } & \multicolumn{3}{|c|}{ Standartlar } \\
\hline & $\mathrm{H}-1 / \mathrm{A}$ & $\mathrm{H} 4$ & HSK & DMSHY, 2004 & ITASHY, 2005 & WHO, 2006 \\
\hline $\mathrm{T}\left({ }^{\circ} \mathrm{C}\right)$ & 56,0 & 56,0 & 11,4 & - & & \\
\hline $\mathrm{pH}$ & 6,53 & 6,56 & 6,75 & - & $6,5-9,5$ & $6,5-8,5$ \\
\hline $\mathrm{EC}(\boldsymbol{\mu} \mathrm{S} / \mathrm{cm})$ & 3490 & 3440 & 1330 & - & - & - \\
\hline TDS $(\mathrm{mg} / \mathrm{l})$ & 2443 & 2408 & 931 & - & - & 1000 \\
\hline $\mathrm{Na}^{+}(\mathrm{mg} /)$ & 401,40 & 395,50 & 70,89 & - & 200 & 200 \\
\hline $\mathrm{K}^{+}(\mathrm{mg} / \mathrm{l})$ & 40,96 & 40,57 & 1,81 & - & - & - \\
\hline $\mathrm{Mg}^{++}(\mathrm{mg} / \mathrm{l})$ & 61,99 & 62,68 & 24,29 & - & - & - \\
\hline $\mathrm{Ca}^{++}(\mathrm{mg} / \mathrm{l})$ & 276,50 & 284,10 & 180,80 & - & - & - \\
\hline $\mathrm{SiO}_{2}\left(\mathrm{mg} / \mathrm{l}^{\circ}\right.$ & 37,78 & 37,50 & 4,98 & - & - & - \\
\hline $\mathrm{Li}(\mathrm{mg} / \mathrm{l})$ & 1,06 & 1,03 & 0,08 & - & - & - \\
\hline $\mathrm{Pb}(\mathrm{mg} / \mathrm{l})$ & $<0,01$ & $<0,01$ & $<0,01$ & 0,01 & 0,01 & 0,01 \\
\hline $\mathrm{Zn}(\mathrm{mg} / \mathrm{l})$ & $<0,01$ & $<0,01$ & $<0,01$ & - & - & - \\
\hline $\mathrm{Cu}(\mathrm{mg} / \mathrm{l})$ & $<0,01$ & $<0,01$ & $<0,01$ & 1 & 2 & 2 \\
\hline $\mathrm{Al}(\mathrm{mg} / \mathrm{l})$ & $<0,01$ & $<0,01$ & $<0,01$ & 0,2 & 0,2 & 0,2 \\
\hline $\mathrm{Fe}(\mathrm{mg} / \mathrm{l})$ & 0,92 & 0,33 & $<0,01$ & - & 0,2 & 0,3 \\
\hline $\mathrm{Mn}(\mathrm{mg} / \mathrm{l})$ & $<0,01$ & $<0,01$ & $<0,01$ & 0,5 & 0,05 & 0,4 \\
\hline $\operatorname{Sr}(\mathrm{mg} /)$ & 1,18 & 0,34 & 0,82 & - & - & - \\
\hline $\mathrm{Sb}(\mathrm{mg} / \mathrm{l})$ & $<0,01$ & $<0,01$ & $<0,01$ & 0,005 & 0,005 & 0,005 \\
\hline As (mg/l) & 0,80 & 0,88 & $<0,01$ & 0,01 & 0,01 & 0,01 \\
\hline $\mathrm{B}(\mathrm{mg} / \mathrm{l})$ & 1,31 & 1,24 & $<0,01$ & - & 1 & 0,5 \\
\hline $\mathrm{Ba}(\mathrm{mg} / \mathrm{l})$ & 0,02 & 0,02 & $<0,01$ & 1 & - & 0,7 \\
\hline $\mathrm{TI}(\mathrm{mg} / \mathrm{l})$ & $<0,01$ & $<0,01$ & $<0,01$ & - & - & - \\
\hline $\mathrm{NO}_{3} \cdot(\mathrm{mg} / \mathrm{l})$ & $<0,10$ & $<0,10$ & 16,61 & 50 & 50 & 50 \\
\hline $\mathrm{NO}_{2}$ (mg/l) & $<0,10$ & $<0,10$ & $<0,10$ & 0,1 & 0,5 & 0,2 \\
\hline $\mathrm{NH}_{4}{ }^{+}(\mathrm{mg} / \mathrm{l})$ & 0,61 & 0,44 & $<0,06$ & - & 0,5 & 1,5 \\
\hline $\left.\mathrm{HCO}_{3} \mathrm{mg} / \mathrm{l}\right)$ & 1464,0 & 1403,0 & 671,0 & - & - & - \\
\hline $\mathrm{PO}_{4}{ }^{2-}(\mathrm{mg} / \mathrm{l})$ & $<0,20$ & $<0,20$ & $<0,20$ & - & - & - \\
\hline $\mathrm{Cl}^{-}(\mathrm{mg} / \mathrm{l})$ & 122,42 & 121,67 & 30,70 & - & 250 & 250 \\
\hline $\mathrm{SO}_{4}^{2-}(\mathrm{mg} / \mathrm{l})$ & 709,98 & 712,98 & 189,45 & - & 250 & 250 \\
\hline$F^{-}(\mathrm{mg} / \mathrm{l})$ & 2,53 & 2,67 & 0,21 & 5 & 1,5 & 1,5 \\
\hline$\%$ YD & $-4,8$ & $-3,5$ & $-4,9$ & - & - & - \\
\hline $\mathrm{SI}_{c}$ (calcite) & 0,642 & 0,666 & 0,032 & - & - & - \\
\hline Slo (dolomite) & 2,228 & 2,269 & 0,425 & - & - & - \\
\hline $\mathrm{Sl}_{q}$ (quartz) & 0,504 & 0,501 & 0,113 & - & - & - \\
\hline
\end{tabular}

Tablo 2. Çalışma alanındaki jeotermal suların silika jeotermometreleri ile hesaplanan rezervuar sıcaklıkları

\begin{tabular}{|c|c|c|c|c|c|c|c|c|c|}
\hline $\begin{array}{c}\text { Ornek } \\
\text { no }\end{array}$ & $\begin{array}{c}\text { Sicaklık } \\
\left({ }^{\circ} \mathrm{C}\right)\end{array}$ & $\begin{array}{c}\text { Kuvars } \\
\text { adyabatik }\end{array}$ & $\begin{array}{c}\text { Kuvars } \\
\text { max. buh. }\end{array}$ & $\begin{array}{c}\text { Kuvars } \\
25-330^{\circ} \mathrm{C}^{\mathrm{b}}\end{array}$ & $\begin{array}{c}\text { Kuvars, } \\
\text { adyabatik }\end{array}$ & $\begin{array}{l}\text { Kuvars } \\
0-350^{\circ} \mathrm{C}^{\circ}\end{array}$ & $\begin{array}{c}\text { Kuvars } 0-350^{\circ} \mathrm{C} \\
\text { adyabatik }^{\circ}\end{array}$ & Kalsedon ${ }^{\mathrm{a}}$ & Kalsedon ${ }^{\circ}$ \\
\hline $\mathrm{H} 1-\mathrm{A}$ & 56,0 & 89,18 & 91,60 & 89,69 & 90,08 & 75,07 & 76,78 & 58,39 & 60,51 \\
\hline $\mathrm{H}-4$ & 56,0 & 88,86 & 91,32 & 89,37 & 89,76 & 74,74 & 76,46 & 58,06 & 60,19 \\
\hline
\end{tabular}

a: Fournier, 1977; b: Fournier and Potter, 1982; c: Arnorsson, 2000; d: Arnorsson ve ark., 1983

Tablo 3. Çalışma alanındaki jeotermal suların katyon jeotermometreleri ile hesaplanan rezervuar sıcaklıkları

\begin{tabular}{|c|c|c|c|c|c|c|c|c|c|c|c|}
\hline $\begin{array}{c}\text { Ornek } \\
\text { no }\end{array}$ & $\begin{array}{c}\text { Sicaklık } \\
\left({ }^{\circ} \mathrm{C}\right)\end{array}$ & $\mathrm{Na}-\mathrm{K}^{\mathrm{a}}$ & $\mathrm{Na}-\mathrm{K}^{\mathrm{b}}$ & $\mathrm{Na}-\mathrm{K}^{\mathrm{c}}$ & $\mathrm{Na}-\mathrm{K}^{\mathrm{d}}$ & $\mathrm{Na}-\mathrm{K}^{\mathrm{e}}$ & $\mathrm{Na}-\mathrm{K}^{\mathrm{f}}$ & $\mathrm{Na}-\mathrm{K}^{\mathrm{g}}$ & $\mathrm{Na}-\mathrm{K}-\mathrm{C} \mathrm{a}^{\mathrm{h}}$ & K-Mgi & Li-Mgj \\
\hline $\mathrm{H} 1-\mathrm{A}$ & 56,00 & 190,15 & 225,53 & 197,21 & 217,29 & 218,87 & 205,62 & 234,07 & 104,23 & 79,30 & 205,35 \\
\hline $\mathrm{H}-4$ & 56,00 & 190,72 & 226,17 & 197,75 & 217,71 & 219,33 & 206,07 & 234,50 & 103,02 & 78,94 & 206,90 \\
\hline
\end{tabular}

a: Truesdell, 1976; b: Tonani, 1980; c: Arnorsson, 1983a; d: Arnorsson, 1983b; e: Fournier, 1979; f: Nivea and Nivea, 1987; g: Giggenbach, 1988; h: Fournier and Truesdell, 1973; i: Giggenbach, 1988; j: Kharaka and Mariner, 1988

\section{b) Birleşik (Kombine) jeotermometre uygulamaları}

Na-K-Mg üçgen diyagramı jeotermal suların kökenini, dengeye ulaşıp ulaşmadıklarının kontrolünü ve uygun jeotermometrelerin seçiminde kullanılır. Giggenbach (1988) tarafından geliştirilen $\mathrm{Na}-\mathrm{K}-\mathrm{Mg}$ jeotermometresi ile jeotermal suyun hem rezervuar sıcaklığı belirlenmekte hemde katyon jeotermometre uygulamasının doğruluğu kontrol edilmektedir. Giggenbach (1988) tarafından geliştirilen $\mathrm{Na}-\mathrm{K}-\mathrm{Mg}$ üçgen diyagramı $\mathrm{Na}-\mathrm{K}$ ve $\mathrm{K}-\mathrm{Mg}$ jeotermometrelerinin üçgen diyagrama aktarılması ile oluşturulmuştur. Na-K-Mg üçgen diyagramına (Giggenbach, 1988) göre Heybeli bölgesindeki jeotermal sular denge durumundan oldukça uzak, olgun olmayan sular grubuna girmektedir. Dolayısıyla bu suların rezervuar sıcaklığının belirlenmesinde katyon jeotermometrelerinin kullanılması hatalı sonuçlar verebilir (Şekil 4). 


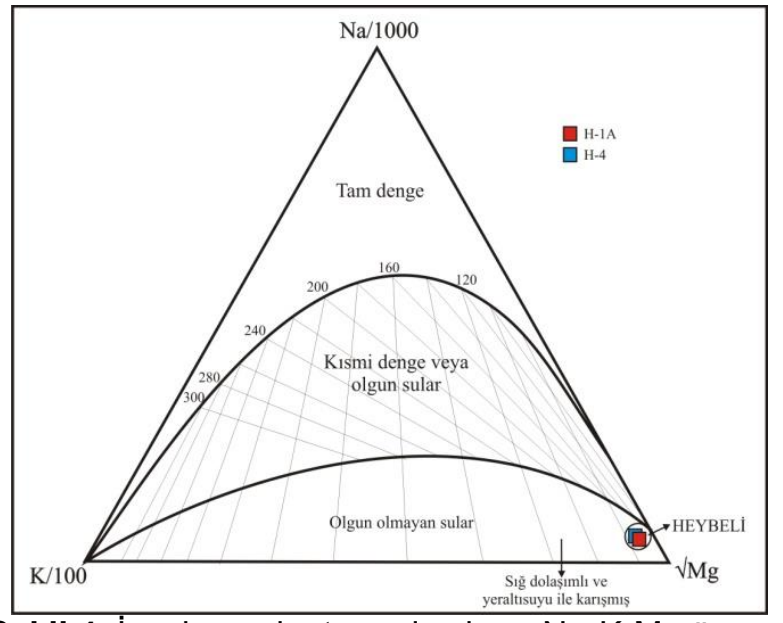

Şekil 4. İncelenen jeotermal suların $\mathrm{Na}-\mathrm{K}-\mathrm{Mg}$ üçgen diyagramı (Giggenbach, 1988)

\section{c) Karışım modelleri}

Karışım modelleri yeni bir jeotermal sahanın rezervuar sıcaklığını belirlemek ya da bir jeotermal sahanın gelişim sürecinde ve sahanın geliştirilmesinde kullanılabilen modellerdir. Jeotermal sular, yüzeye çıkış sırasında diğer sularla karışabilir. Silika ve klorür miktarının jeotermal suyun kökeninde olduğu gibi korunduğu varsayılarak, Entalpi-Silika (Fournier, 1977) ve Entalpi-Klorür (Truesdell and Fournier, 1975) değişimi ile karışım oranları, maksimum hazne kaya sıcaklığı açıklanabilir. Çalışma alanındaki jeotermal suların entalpi-silika karışım modeli, kalsedon ve kuvarsa göre sırasıyla yaklaşık 82 ve $106{ }^{\circ} \mathrm{C}$ bir rezervuar sıcaklıkları önermektedirler (Şekil 5). Bu da kuvars jeotermometresi ile hesaplanan $\left(75-90^{\circ} \mathrm{C}\right)$ rezervuar sıcaklığı ile uyumludur.

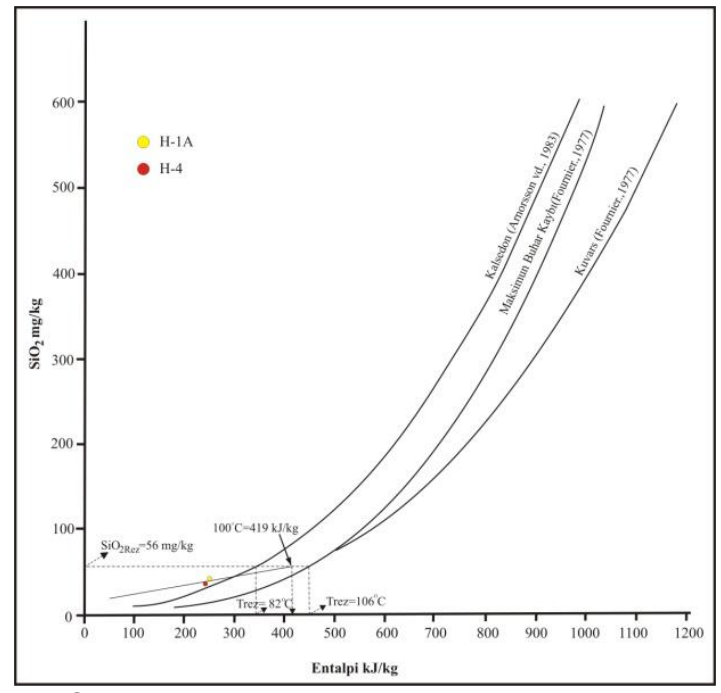

Şekil 5. Çalışma alanındaki jeotermal sulara ait EntalpiSilika diyagramı
Entalpi-klorür diyagramının oluşturulmasında, genellikle silika jeotermometreleriyle hesaplanan sıcaklıklar kullanılır. Çalışma alanı jeotermal suları için oluşturulan iki ayrı diyagramda, kalsedon ve kuvars (adyabatik soğuma) jeotermometrelerinden yararlanılmıştır. Kalsedon jeotermometresi (Arnorsson et al.,1983a,b) kullanılarak hazırlanan diyagram $63^{\circ} \mathrm{C}$ 'lik bir rezervuar sıcaklığını işaret eder (Şekil 6). Kuvars (adyabatik soğuma) jeotermometresi (Fournier, 1977) kullanılarak hazırlanan diyagram ise $84^{\circ} \mathrm{C}$ 'lik bir rezervuar sıcaklığı göstermektedir (Şekil 7).

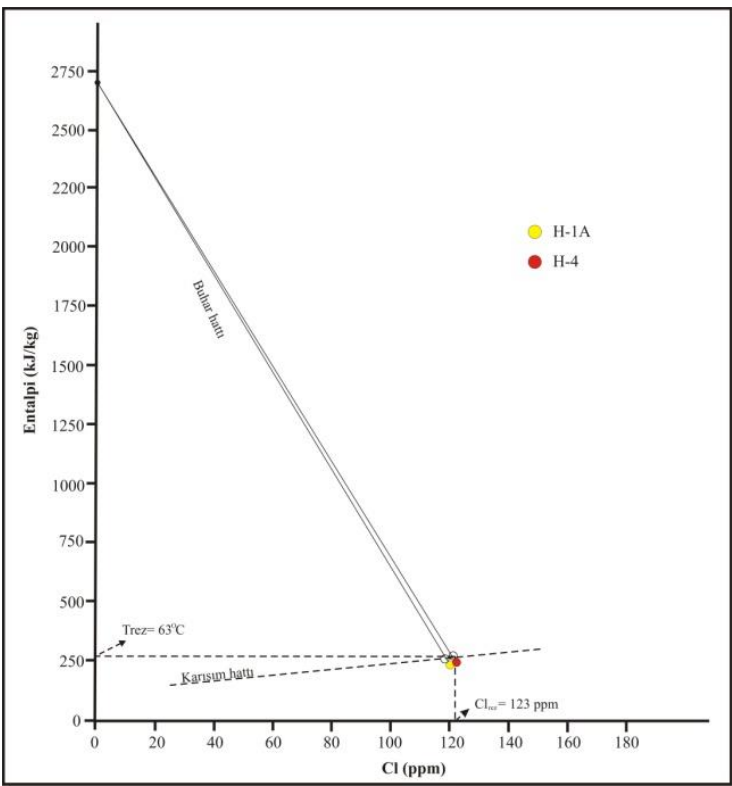

Şekil 6. Çalışma alanındaki jeotermal sulara ait EntalpiKlor diyagramı (Kalsedon)

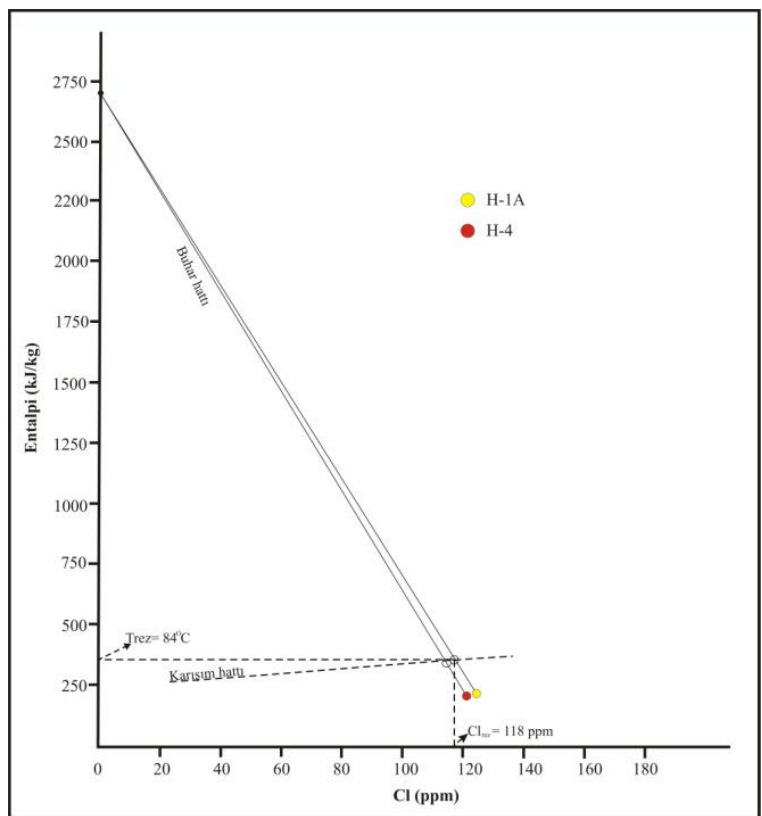

Şekil 7. Çalışma alanındaki jeotermal sulara ait EntalpiKlor diyagramı (Kuvars) 


\section{d) Mineral denge-sıcaklık diyagramı jeotermometreleri}

$\mathrm{Bu}$ yöntem suyun kimyasal analizi sonucunda çeşitli mineraller ile bu minerallerin her bir sıcaklık değerinde ayrı ayrı doygunluk indekslerinin hesaplanması ve bu sıcaklık değerleri ile doygunluk indeksi değerlerinin bire bir doğrularını içeren mineral denge diyagramlarının çizilerek yorumlanması ilişkisine dayanır. Bu yorumlamada, minerallerin çözünürlük denge sabitleri sıcaklıkla yakın ilişkili olduğundan, bir grup mineral doğrusu denge doğrusunu (SI=0 doğrusunu) belirli bir sıcaklık değeri civarında kesiyorsa, bu doğruların kesişim yerine karşıık gelen sıcaklık değeri en iyi akifer sıcaklığını vermektedir (Tarcan, 2002). Solmineq.88 (Kharaka et al., 1988) bilgisayar programı kullanılarak, her bir mineral için çeşitli sıcaklıklarda (1 atm basınç koşulunda) doygunluk indeksleri $(\mathrm{SI}=\log \mathrm{Q} / \mathrm{K}=\log \mathrm{AP} / \mathrm{Kt})$ ayrı ayrı hesaplanmıştır. Bu sıcaklık değerlerine karşılık gelen doygunluk indeksi değerleri, her bir mineral ve sıcaklık için en iyi doğrusal ilişki verecek şekilde doğruları çizilerek "Sıcaklık-Mineral Denge" diyagramları oluşturulmuştur. Heybeli jeotermal sularının sıcaklık-mineral denge diyagramlarına göre (Şekil 8) eğrilerin yaklaşık denge durumunda kesiştikleri yer olan $75-100{ }^{\circ} \mathrm{C}$ arasındaki sıcaklık değerlerinin bölgenin rezervuar sıcaklıkları olduğu şeklinde yorumlanabilir.

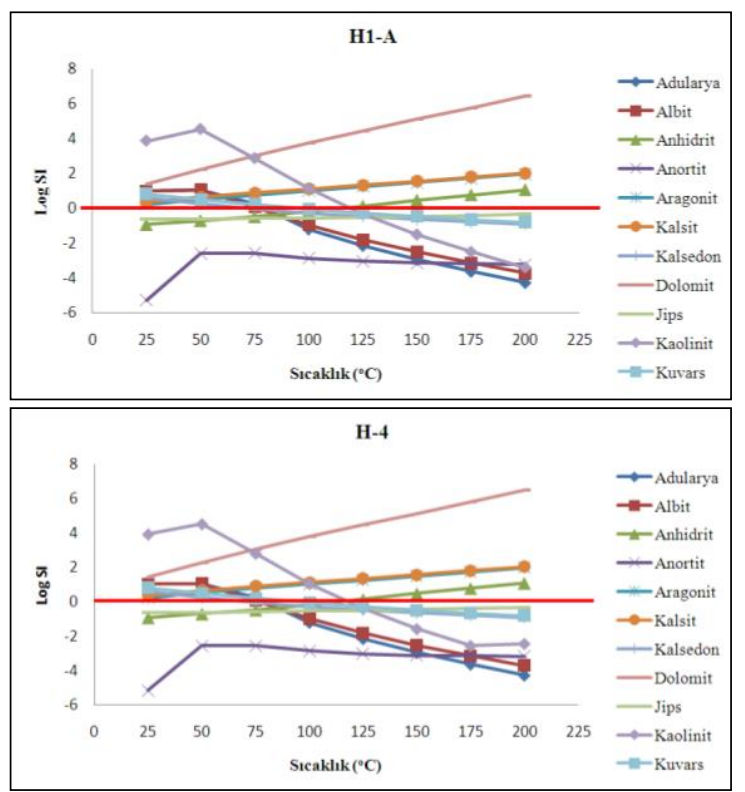

Şekil 8. Heybeli jeotermal sularının sıcaklık-mineral denge diyagramları

\section{SONUÇLAR}

Afyonkarahisar-Heybeli jeotermal alanındaki jeotermal sular $\mathrm{Na}-(\mathrm{Ca})-\mathrm{HCO}_{3}-\mathrm{SO}_{4}$ tipli sular olarak tanımlanmış- tır. Yeraltısuları ise $\mathrm{Ca}-(\mathrm{Na})-\mathrm{HCO}_{3}-\left(\mathrm{SO}_{4}\right)$ tipinde sulardır. Jeotermal suların TDS, $\mathrm{Na}, \mathrm{SO}_{4}, \mathrm{~F}, \mathrm{Fe}, \mathrm{As}$, B değerlerinin ulusal ve uluslararası içme suyu standartları$\mathrm{nı}$ aştığı gözlenmiştir. Na-K-Mg üçgen diyagramına göre Heybeli bölgesindeki jeotermal sular denge durumundan oldukça uzak, olgun olmayan sular grubuna girmektedir. Bu nedenle katyon jeotermometrelerine şüphe ile yaklaşmak gerekir. Kalsedon jeotermometreleri ile hesaplanan rezervuar sıcaklıkları ise kuyu başı sıcaklığına yakındır. Bu nedenle kuvars jeotermometreleri ile hesaplanan rezervuar sıcaklığı değerleri Heybeli bölgesindeki jeotermal suların rezervuar sıcaklığını daha iyi yansıtmaktadır. Çalışma alanındaki jeotermal suların kuvars jeotermometreleri ile $75-90^{\circ} \mathrm{C}$; entalpisilika karışım modeline göre $82-106{ }^{\circ} \mathrm{C}$; entalpi-klorür karışım modeline göre ise $63-84{ }^{\circ} \mathrm{C}$; sıcaklık-mineral denge diyagramlarında ise $75-100^{\circ} \mathrm{C}$ arasındaki sıcaklık değerleri hesaplanmıştır. Sonuç olarak Heybeli jeotermal sularının rezervuar sıcaklığı $75-106^{\circ} \mathrm{C}$ arasındadır.

\section{KAYNAKLAR}

Akkuş, İ., Akıllı, H., Ceyhan, S., Dilemre, A., Tekin, Z. (2005). MTA Türkiye Jeotermal Kaynakları Envanteri, 849s., Ankara.

APHA-AWWA-WEF (2005). Standard Methods for the Examination of Water and Wastewater. 21st edition, In: Eaton, A.D., Clesceri, L.S., Rice, E.W., Greenberg, A.E. (eds), American Public Health Association, Washington, D.C.

Arnorsson, S. (2000). Isotopic and Chemical Techniques in Geothermal Development and Use, Vienna: International Atomic Energy Agency.

Arnorsson, S., Gunnlaugsson, E., Svavarsson, H. (1983a). The Chemistry of Geothermal Waters in Iceland-III. Chemical Geothermometry in Geothermal Investigations. Geochim. Cosmochim. Acta, 47, 567-577.

Arnorsson, S., Gunnlaugsson, E. Svavarsson, H. (1983b). The Chemistry of Geothermal Waters in Iceland-II. Mineral Equilibria and Independent Variables Controlling Water Compositions, Geochim. Cosmochim. Acta, 47, 547-566.

Calmbach, L. (1999). AquaChem Computer Code-Version 3.7: Aqueous geochemical analyses, plotting and modelling, Waterloo Hydrogeologic, Waterloo, Ontario, Canada, $184 \mathrm{p}$.

Demer, S. ve Memiş, Ü., 2015. Afyonkarahisar Jeotermal Sahalarının Hidrojeokimyası ve Jeotermometre Uygulamaları. Süleyman Demirel Üniversitesi Fen Bilimleri Enstitüsü Dergisi, 19, 2, 66-77.

DMSHY (2004). Doğal Mineralli Sular Hakkında Yönetmelik, 1 Aralık 2004, Sayı: 25657, Sağlık Bakanlığı, Ankara.

Erişen, B. (1972). Afyon-Heybeli (Kızılkilise) araştırma sahasının jeolojisi ve jeotermal olanakları. MTA Rapor No. 5490, 74s., (yayınlanmamış), Ankara.

Erişen, B., Akbaşlı, A., Can, A. R. (1984). Ayfon-Çay, Karaburun sıcaksu sondajı kuyu bitirme raporu. MTA raporu, No: 8267 (yayınlanmamış) 
Fournier, R. O. (1977). Chemical Geothermometers and Mixing Models for Geothermal Systems. Geothermics, 5, 41-50.

Fournier, R. O. (1979). A revised equation for the Na-K geothermometer. Geothermal Res. Council Trans., 3, 221224.

Fournier, R. O., Potter, R. W. (1982). An Equation Correlating the Solubility of Quartz in Water from $25^{\circ}$ to $900{ }^{\circ} \mathrm{C}$ at Pressures up to 10.000 bars. Geochim. Cosmochim. Acta, 46, 1969-1974.

Fournier, R. O., Truesdell, A. H. (1973). An empirical Na-K$\mathrm{Ca}$ geothermometer for natural waters. Geochim. Cosmochim. Acta, 37, 1355-1275.

Gemici, Ü., Tarcan, G. (2004). Hydrogeological and hydrogeochemical features of the Heybeli Spa, Afyon, Turkey: Arsenic and other contaminants in the thermal waters. Bull. Environ. Contam. Toxicol., 72, 1107-1114.

Gırbalar, Ö. E. (2008). Heybeli (Kızılkilise) jeotermal sahası kuyuları sıcaklık, basınç ve test verileri üzerine bir değerlendirme. 5. Dünya Su Forumu, Termal ve Maden Suları Konferansı, Bildiriler, 24-25 Nisan 2008, 55-69 s., Afyonkarahisar.

Giggenbach, W.F. (1988). Geothermal Solute Equilibria. Derivation of Na-K-Mg-Ca Geoindicators. Geochim Cosmochim Acta, 52, 2749-2765.

ITASHY, 2005. Sular - İnsani Tüketim Amaçlı Sular, TS-266, Türk Standartları Enstitüsü, Ankara.

Kharaka, Y. K., Mariner, R. H. (1988). Chemical Geothermometers and Their Application to Formation Waters from Sedimentary Basins. In Naeser, N. D. and McCollin, T. H., editors, Thermal History of Sedimantary Basins, SpringerVerlag, 99-117.
Kharaka, Y.K., Gunter, W.D., Aggarwal, P.K., Perkins, E.H., Debraal, J.D. (1988). SOLMINEQ.88: A computer program for geochemical modeling of water-rock interactions, U.S. Geol. Surv. Water Res. Inv. Rep. 88-4227, 420 p.

Mutlu, H. (1996). Geochemical assesment of thermal waters from the Afyon geothermal area: Geothermometry applications and fluid-mineral equilibria., Ph. D. Thesis,, Middle East Technical University, Graduate School of Natural and Applied Sciences, 169p (yayımlanmamış), Ankara.

Nivea, D., Nivea R. (1987). Developments in Geothermal Energy in Mexico. Part 12, A Cationic Geothermometer for Prospecting of Geothermal Resources. Heat Recovery Systems and CHP, 7, 243-258.

Tarcan, G. (2002). Jeotermal Su Kimyası. Jeotermal Enerji Araştırma ve Uygulama Merkezi (Jenarum) Yaz Okulu Ders Notları, 230-272, İzmir.

Tonani, F. (1980). Some Remarks on the Application of Geochemical Techniques in Geothermal Exploration. Proceedings, Adv. Eur. Geoth. Res. Second Symp., 428-443.

Truesdell, A. H. (1976). Summary of Section III Geochemical Techniques in Exploration. In Proceedings, Second United Nations Symposium on the Development and Use of Geothermal Resources, San Francisco, CA, U. S. Government Printing Office, 1, 13-39, Washington, D.C.

Truesdell, A.H., Fournier, R.O. (1975). Calculation of Deep Temperatures in Geothermal Systems form the Chemistry of Boiling Spring Waters of Mixed Origin. Proc. Second UN Symposiumon Geothermal Resources, San Franscisco, CA, 837-844.

WHO (2006). World Health Organization (WHO), Guidelines for Drinking Water Quality, Volume 2, Health Criteria and Other Supporting Information: WHO Publ., Geneva, Switzerland, $335 \mathrm{p}$. 